Article

\title{
Prediction of Eddy Current Losses in Cooling Tubes of Direct Cooled Windings in Electric Machines
}

\author{
Mohamed Nabil Fathy Ibrahim 1,2,3,*(D) and Peter Sergeant ${ }^{1,2}(\mathbb{D}$ \\ 1 Department of Electrical Energy, Metals, Mechanical Constructions and Systems, Ghent University, \\ 9000 Ghent, Belgium; peter.sergeant@ugent.be \\ 2 FlandersMake@UGent-corelab EEDT-MP, 3001 Leuven, Belgium \\ 3 Electrical Engineering Department, Kafrelshiekh University, Kafr el-Sheikh 33511, Egypt \\ * Correspondence: m.nabil@ugent.be or m.nabil@eng.kfs.edu.eg
}

Received: 26 October 2019; Accepted: 9 November 2019; Published: 13 November 2019

\begin{abstract}
The direct coil cooling method is one of the existing cooling techniques for electric machines with concentrated windings, in which cooling tubes of conductive material are inserted between the windings. In such cases, eddy current losses are induced in those cooling tubes because of the time variant magnetic field. To compute the cooling tubes losses, either a transient finite element simulation (mostly based on commercial software), or a full analytical method, which is more complex to be constructed, is required. Instead, this paper proposes a simple and an accurate combined semi-analytical-finite element method to calculate the losses of electric machines having cooling tubes. The 2D magnetostatic solution of the magnetic field is obtained e.g., using the free package "FEMM". Then, the eddy current losses in the tubes are computed using simple analytical equations. In addition, the iron core losses could be obtained. In order to validate the proposed method, two cases are investigated. In Case 1, a six-toothed stator of a switched reluctance machine (SRM), without rotor, is employed in which six cooling tubes are used while in Case 2 a complete rotating SRM is studied. The proposed method is validated by a 2D transient simulation in the commercial software "ANSYS Maxwell" and also by experimental measurements. Evidently, the proposed method is simple and fast to be constructed and it is almost free of cost.
\end{abstract}

Keywords: analytical models; cooling tubes; electric machines; magnetic losses; numerical models; finite element method; switched reluctance machines

\section{Introduction}

Electric machines of high power density and small volume have been receiving great interest in several industrial applications e.g., in electric vehicles in which there are constraints on the motor size and a necessary power density is required depending on the driving cycle [1,2]. Therefore, researchers are investigating several possibilities to improve the power per volume of the electric machines. This can be achieved by improving the electromagnetic and the thermal behaviors of the machine [1-8]. The electromagnetic behavior of the motor includes optimal geometrical selection and optimal drive system whilst the thermal behavior includes better heat extraction from the motor using a cooling system. It is necessary to combine both the electromagnetic and thermal behaviors so that an optimal motor performance can be achieved [9-11].

Several cooling techniques to improve the thermal behavior of electric machines can be found in the literature [12-14], among them the so-called "direct coil cooling technique". The direct coil cooling method is employed in several electric machines, in particular for a toothed stator with concentrated windings $[15,16]$. This is because in those machines, there is unused areas between the windings due to some geometric constraints; for instance, Figure 1 shows a drawing of a six-toothed stator core 
with concentrated windings which can be used in several electric machines e.g., switched reluctance machines, brushless DC machines, etc. [16,17]. Cooling tubes can be inserted in the space between the windings of the machine in which a liquid (water or oil) flows as sketched in Figure 1. In this way, the heat of the windings could be extracted much faster and efficiently compared to the other cooling techniques e.g., water jacket method $[12,14,16]$. Consequently, the current in the windings might be increased, and hence the machine power per fixed volume can be improved $[16,18]$. Several literature works have investigated the influence of using the direct coil (slot cooling) technique on the thermal behavior of the electric machines [15,16]. For example, in Reference [18] an interior permanent magnet synchronous machine (IPMSM) with a conventional round wire winding and water jacket cooling is compared with rectangular flat wires and slot cooling. It was found that the slot cooling technique could be considered as an effective cooling method for both stator and rotor geometries. In addition, the absence of a water jacket results in a more compact and a comparable machine cost. However, when the cooling tubes are inserted between the stator windings, induced eddy current losses occur in them because of the time variant magnetic field. To estimate the efficiency of the machine, the cooling tube losses should be obtained. Hence, a transient time solution is necessary to accurately obtain the losses of the tubes. This solution could be based on completely analytical or numerical models (finite element model) [19]. The analytical model has the advantage of the low computation time to get the solution, however it is more complex and may include some assumptions as indicated in Reference [20]; it is necessary to model not only the cooling tube but also the complete system because the leakage magnetic field in the tube is mandatory to obtain the losses. Thus, this costs time and effort to be constructed. In contrast, the finite element model (FEM) is more accurate and can be implemented faster. However, it consumes large amounts of time to obtain the solution [1-3]. In addition, the packages available are mostly commercial with an expensive cost. Therefore, a combined model of the analytical and free 2D FEM package, which is called a "combined semi-analytical-FEM", could be a promising method.

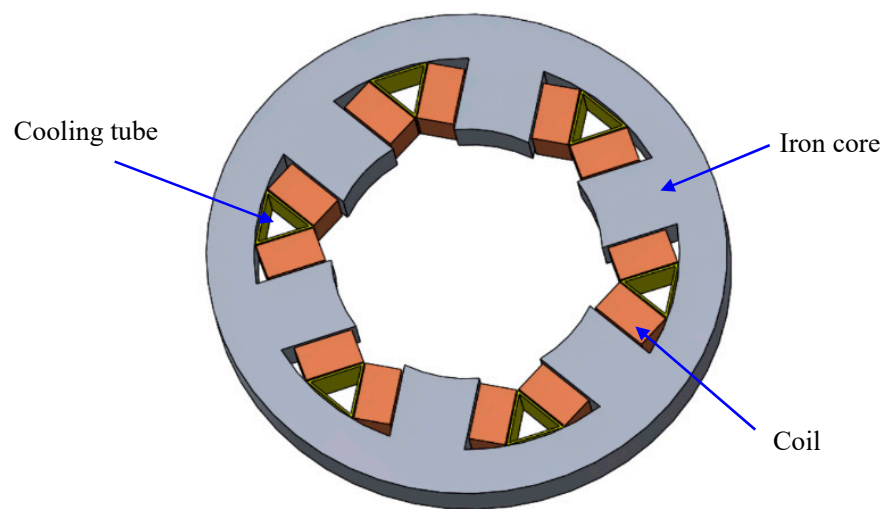

Figure 1. Six-toothed stator from an electric machine with concentrated windings.

The main contribution of this work was to propose a semi-analytical based FEM method in order to compute the eddy current losses in the cooling tubes. In addition, the proposed method could be applied to compute the iron core loses. The proposed method was based on 2D magnetostatic free package "FEMM" coupled with some simple analytical equations. This method could be constructed quickly, and generally for any electric device e.g., motor. In addition, it was almost free of cost and hence there was no need for commercial finite element packages. 


\section{Semi-Analytical Based Finite Element Loss Model}

The electrical losses in electric machines include mainly the copper and the iron core losses. When a cooling tube of conductive material is inserted between the machine windings, eddy current loss will be induced, resulting in an additional loss in the machine. This loss can be computed by [21,22]:

$$
\begin{gathered}
J_{\text {tube }}=-\sigma \frac{\partial A}{\partial t}, \\
P_{\text {tube }}=\int \frac{J_{\text {tube }}^{2}}{\sigma} d(v o l),
\end{gathered}
$$

where $J_{\text {tube }}, \sigma, A$, vol and $P_{\text {tube }}$ are the current density, material electrical conductivity, magnetic vector potential, volume and the computed eddy current loss in the tube respectively.

The iron losses consist of three main components: hysteresis loss, classical eddy current loss and excess loss; each of them depends on the flux density waveform (amplitude and frequency), and also on the magnetic steel grade. Assuming a sinusoidal flux density waveform, the iron core losses in electric machines are obtained as in Reference [4] by:

$$
\begin{gathered}
P_{h y}=k_{1} B_{m}^{k_{2}} f, \\
P_{c l}(t)=k_{3}\left|\frac{d B(t)}{d t}\right|^{2}, \\
P_{e x}(t)=k_{4}\left(\sqrt{1+k_{5}\left|\frac{d B(t)}{d t}\right|}-1\right)\left|\frac{d B(t)}{d t}\right|, \\
P_{\text {iron }}=\left(P_{h y}+P_{c l}+P_{e x}\right) \rho,
\end{gathered}
$$

where $k_{1}, k_{2}, k_{3}, k_{4}$ and $\rho$ are material dependent parameters, $B(t)$ and $B_{m}$ are the instantaneous and peak flux densities in the machine and $f$ is the frequency of the applied field.

The previous formula of the hysteresis loss i.e., $P_{h y}$ in Equation (3) assumes that the flux density in the machine is a pure sinusoidal waveform. This assumption is not correct in electric machines fed from an inverter. In addition, some of the electric machines, e.g., switched reluctance machine, have asymmetric flux waveforms due to their construction. This means that the formula of Equation (3) cannot predict the hysteresis loss accurately in the case of asymmetric flux waveforms or inverter fed electric machines. Consequently, in the literature improved iron loss models are presented in order to take into account the influence of the asymmetric flux waveforms and the pulse width modulation (PWM) of the inverter as in References [23-25]. The improved iron loss model presented in Reference [24] is integrated in Equation (3) to consider the aforementioned effects. The instantaneous hysteresis loss is then calculated by:

$$
\begin{gathered}
P_{h}(t)=H_{i r r} \frac{d B(t)}{d t}, \\
H_{i r r}=\frac{1}{\pi} c_{d} B_{m} \cos (\theta), \\
c_{d}=1+k_{d c} B_{d c}^{d m},
\end{gathered}
$$

where $H_{i r}$ is the irreversible component of the magnetic field which is associated with the hysteresis loss; $\theta$ represents the position in the hysteresis loop at the current moment and $k_{d c}$ and $d_{m}$ are constants and equal 0.65 and 2.1 respectively. More details about this loss model is given in References [23-25].

Moreover, knowing the current and the resistance of the machine windings, the copper losses can be simply computed by:

$$
P_{c u}=m I_{p h}^{2} R_{p h},
$$


where $m, I_{p h}$ and $R_{p h}$ are the number of phases, the root mean square of the phase current and the phase resistance respectively.

The resistance of the coil depends on the length, cross section area and the material resistivity of the coil, which can be obtained for the studied geometry.

From the previous equations, it was observed that the main parameters of loss model of the cooling tube and the iron core are the magnetic vector potential $(A)$, the flux density $(B)$ and some fixed geometrical parameters such as the volumes of the tube wall and the iron core. To obtain these parameters, the electric machine or device was simulated by 2D magnetostatic computations, e.g., using the free package "FEMM", at different time instants. The values of the magnetic vector potential, the flux density and the volume in the mesh elements of the cooling tube wall and the iron core were then recorded at each time instant. Eventually, the tube and the iron core losses were computed using Equations (1)-(9).

\section{Case Studies}

In order to examine the aforementioned proposed loss approach, two cases were studied. Case 1 considered only a stator with six concentrated coils and six cooling tubes as sketched in Figure 1 . This case was referred to as "a stator setup case". A full rotating switched reluctance motor was considered as Case 2.

\subsection{Stator Setup}

A stator with six teeth (outer/inner diameters were $120 / 62.5 \mathrm{~mm}$, the stack length was $80 \mathrm{~mm}$ and the steel type was NO20, see Table 1), was built in FEMM, in which the cooling tubes were inserted between the windings as shown in Figure 1. The maximum air gap length between the coil and the tube and the stator yoke and the tube were 0.25 and $0.7 \mathrm{~mm}$ respectively. Obviously, there was no rotor included; this was for an accurate characterization of the tubes' losses. The tube material was a stainless steel of an electrical conductivity of $1.35 \mathrm{MS} / \mathrm{m}$ and with a wall thickness of $1 \mathrm{~mm}$. An electrical insulation material, e.g., polyimide film, covered the cooling tubes to guarantee a complete electrical insulation between the cooling tubes and the coils as seen in the experimental validation section. Each stator tooth had a concentrated coil of 25 turns. The six coils were connected in series (A-B+, B-C+, $\mathrm{C}-\mathrm{D}+, \mathrm{D}-\mathrm{E}+, \mathrm{E}-\mathrm{F}+$ ) as seen in Figure 2. The coils were supplied from a sinusoidal AC supply and hence a sinusoidal current passed though the coils. This resulted in flux lines distributions as seen in Figure 2. It is evident from Figure 2 that some flux lines passed through the cooling tubes i.e., called "leakage flux". The flux level varied with the time, resulting in induced eddy currents in the tubes. Thus, eddy current losses were generated in the tubes. The mesh elements of part of the stator geometry are shown in Figure 3. The flux density, magnetic vector potential and the volume of each mesh element of stator core and tubes were recorded from FEMM at each time instant.

Table 1. Switched reluctance motor (SRM) parameters.

\begin{tabular}{cccc}
\hline Stator/Rotor Poles & $\mathbf{6 / 4}$ & Active Axial Length & $\mathbf{8 0 ~ \mathbf { ~ m }}$ \\
\hline Stator outer diameter & $120 \mathrm{~mm}$ & Turns/pole & 25 \\
Stator inner diameter & $62.5 \mathrm{~mm}$ & Rated speed & $3000 \mathrm{rpm}$ \\
Stator and rotor yoke thickness & $11 \mathrm{~mm}$ & Rated current & $60 \mathrm{~A}$ \\
Stator and rotor pole width & $17.5 \mathrm{~mm}$ & DC bus voltage & $300 \mathrm{~V}$ \\
Rotor outer diameter & $62 \mathrm{~mm}$ & Rated power & $3 \mathrm{~kW}$ \\
Shaft diameter & $20 \mathrm{~mm}$ & Steel type & NO20 \\
\hline
\end{tabular}




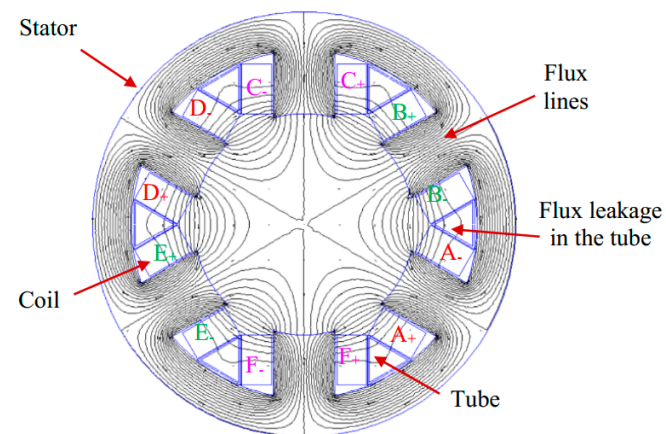

(a) FEMM

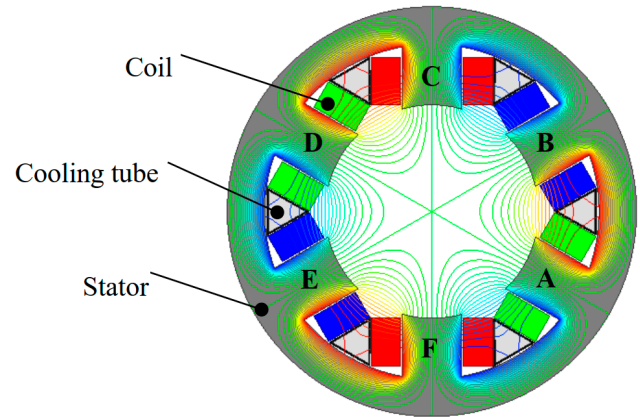

(b) ANSYS Maxwell

Figure 2. Stator with six teeth with inserted six metal tubes. Notice that the rotor was removed, for accurate characterization of the tubes' losses.

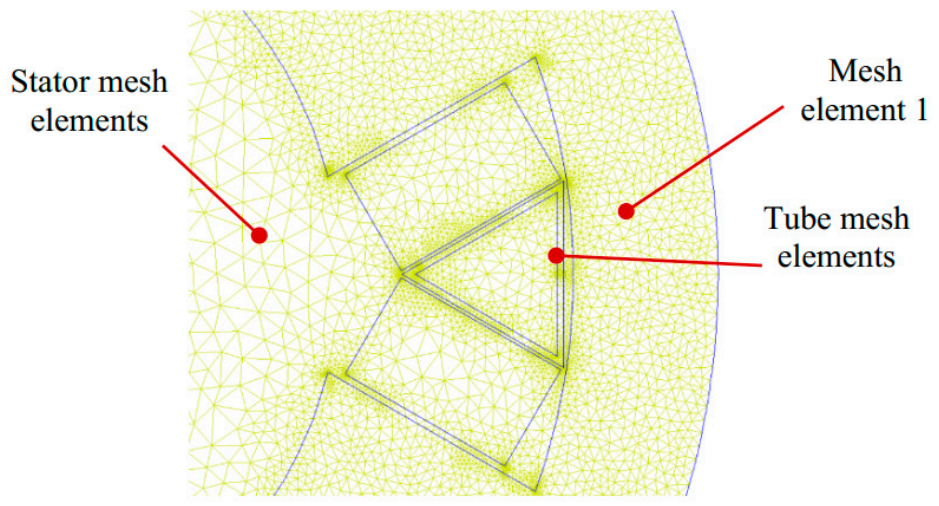

Figure 3. Mesh elements of the stator geometry.

For example, Figure 4 shows the flux density and magnetic vector potential as functions of time for Mesh Element 1 (see Figure 3) at $40 \mathrm{~A}$ and $500 \mathrm{~Hz}$. Eventually, the losses could be calculated using the aforementioned equations (Section 2) as reported in Figures 5 and 6. Figures 5 and 6 show the losses of the stator iron core and the cooling tubes respectively at several supply currents (RMS) and frequencies: the values of the current (RMS) and frequency ranged up to $42 \mathrm{~A}\left(14.80 \mathrm{~A} / \mathrm{mm}^{2}\right)$ and $1000 \mathrm{~Hz}$ respectively. It was obvious that the tubes losses ranged from about $2.40 \%$ to $14.49 \%$, depending on the flux amplitude and frequency, compared to the iron losses for the studied case. This meant that the tube loss could be significant depending on the application. Further, Figures 5 and 6 clearly demonstrate that the computed losses using the proposed method corresponded very well with those obtained by the 2D transient FEM simulations of the "ANSYS Maxwell" package. It is important to note that to obtain an accurate loss calculation using the proposed method, the number of time steps per electric period of the field solution should be enough.

\subsection{Switched Reluctance Motor}

The 6/4 switched reluctance motor (SRM) shown in Figure 7 with the geometrical parameters listed in Table 1 was simulated using both the proposed semi-analytical based FEMM and ANSYS Maxwell packages. Six cooling tubes were inserted in the triangular prism gap between the coils as seen in Figure 7. Figure 8 shows the flux lines of the SRM at a peak current of $60 \mathrm{~A}$ in one phase (A) using both FEMM and ANSYS Maxwell packages. In this study, an ideal current waveform was used as shown in Figure 9. 

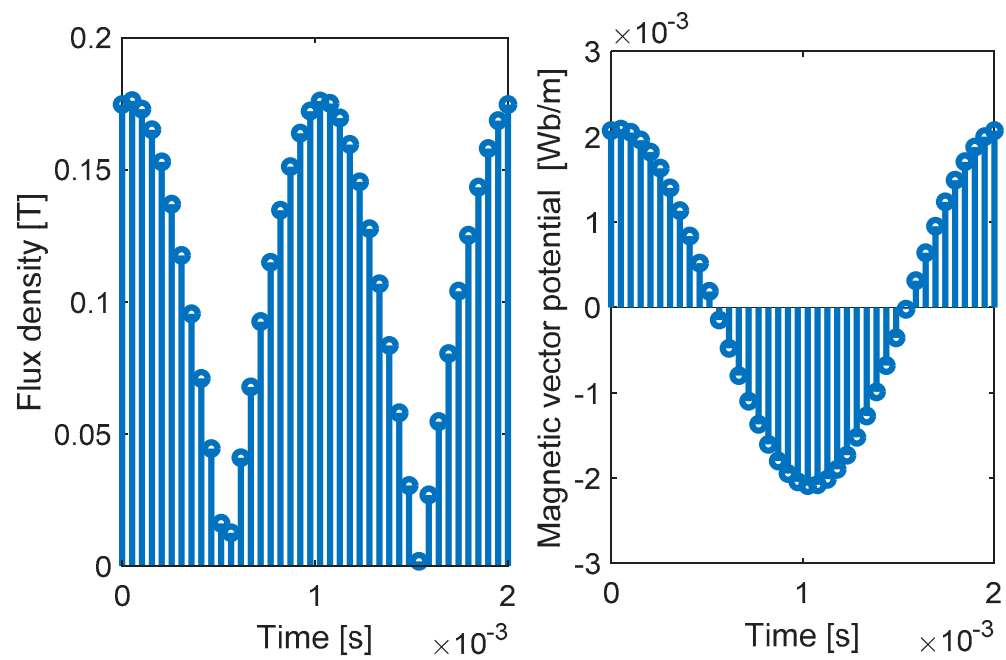

Figure 4. Flux density (right) and magnetic vector potential (left) as functions of time for Mesh Element 1 at $40 \mathrm{~A}$ and $500 \mathrm{~Hz}$.

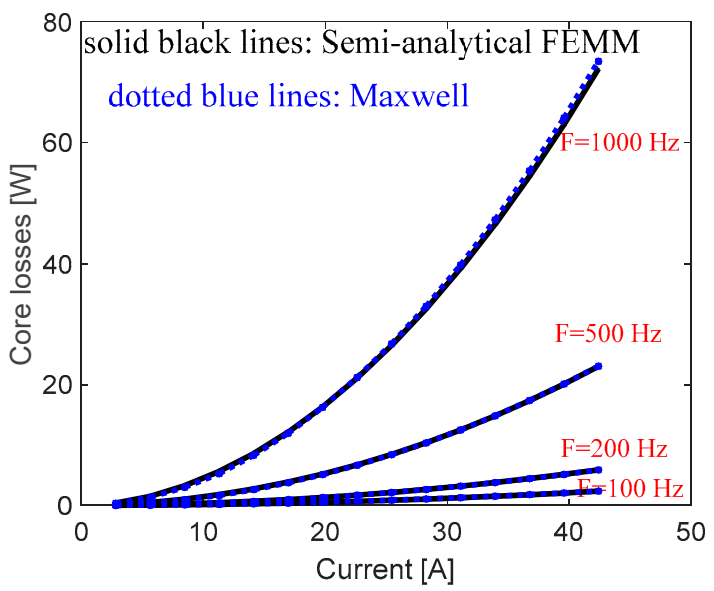

Figure 5. Core losses of the stator for different supply currents and frequencies.

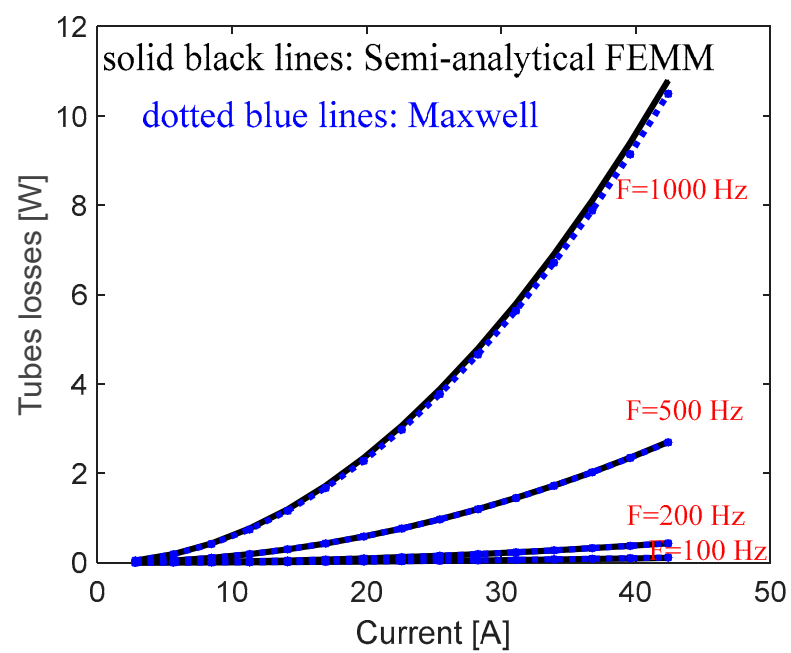

Figure 6. Tubes losses of the stator for different supply currents and frequencies. 


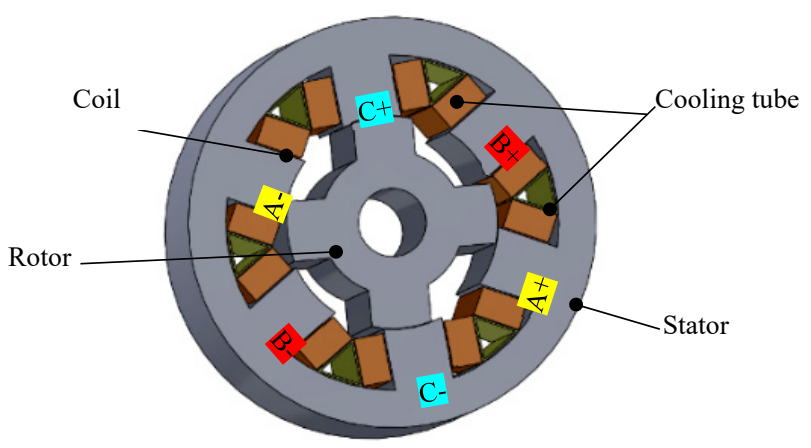

Figure 7. The 6/4 SRM geometry.

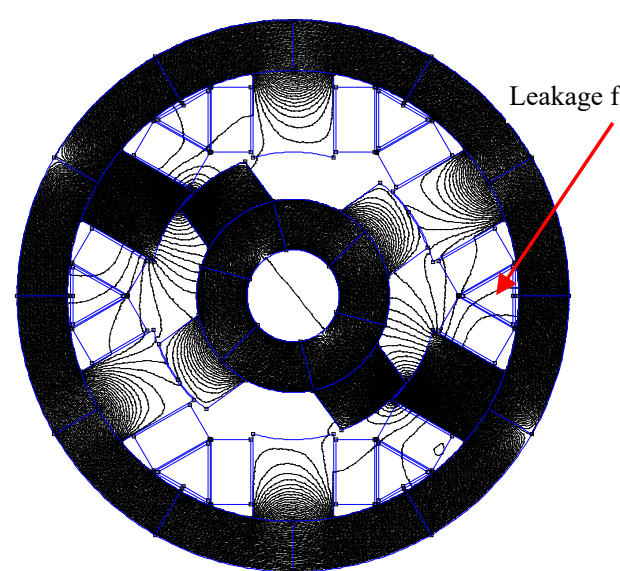

(a) FEMM

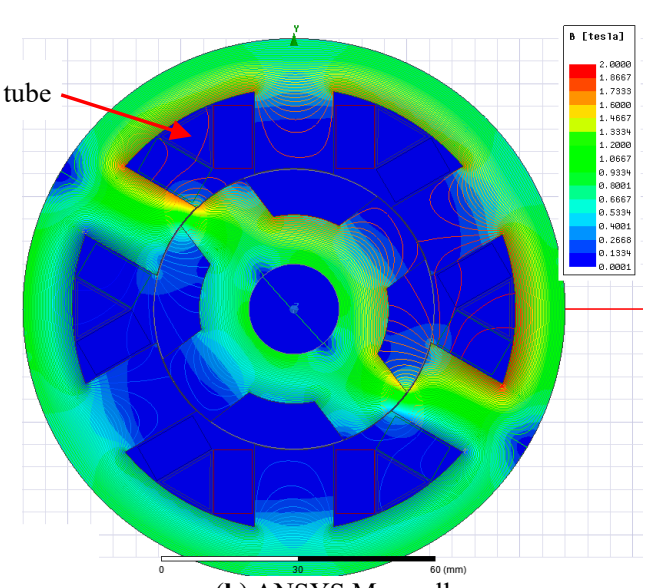

(b) ANSYS Maxwell

Figure 8. Flux distribution of the SRM at $2000 \mathrm{rpm}$ and current amplitude of $60 \mathrm{~A}$ for one rotor position $\left(43.2^{\circ}\right)$.

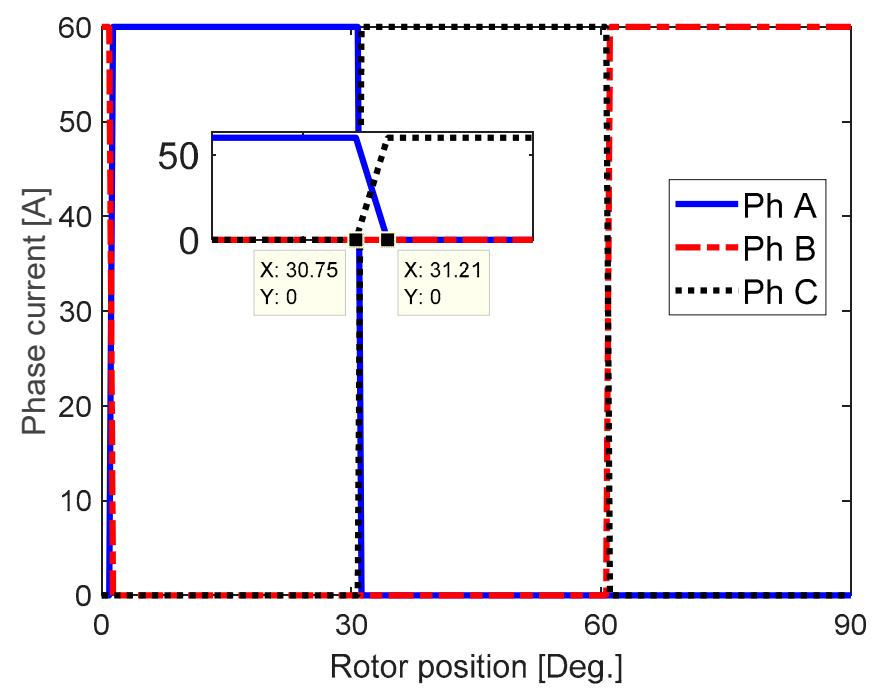

Figure 9. Currents in the phases of the SRM.

Figure 10 shows the output torque of the SRM as a function of the current amplitude at $2000 \mathrm{rpm}$ using both FEMM and Ansys models. The torque increased approximately in a linear way with the peak value of the current. Clearly, the output torque of both packages was similar. Figure 11 reports the core losses of the machine as a function of the current amplitude at $2000 \mathrm{rpm}$. It was noticed that there was a slight difference of about $2 \%$ in the core losses between the proposed loss method and ANSYS Maxwell. The reason was that in the proposed loss model the constant values in Equation (4) were assumed valid for different material thicknesses. However, in Reference [23] it is mentioned that the 
constants in Equation (4) vary with the thickness of the magnetic steel grade. Further, the used values ( 0.65 and 2.1) were the average values obtained by measurements for various steel grade thicknesses from Reference [23] and could be accepted. Figure 12 shows the eddy current loss of the cooling tubes as a function of the stator peak current at an SRM speed of $2000 \mathrm{rpm}$. At $60 \mathrm{~A}$, the tubes losses of the proposed method and ANSYS Maxwell were $2.03 \mathrm{~W}$ and $2.13 \mathrm{~W}$ respectively. This showed that the proposed method was capable of predicting the eddy current losses in the cooling tube. This loss represented about $0.1 \%$ of the motor output power, which could be neglected in this case. This was because an ideal current waveform was used in this case. However, in the real current waveform there would be an interference between the currents of the phases as well as harmonics, which would result in an increase in the tube losses.

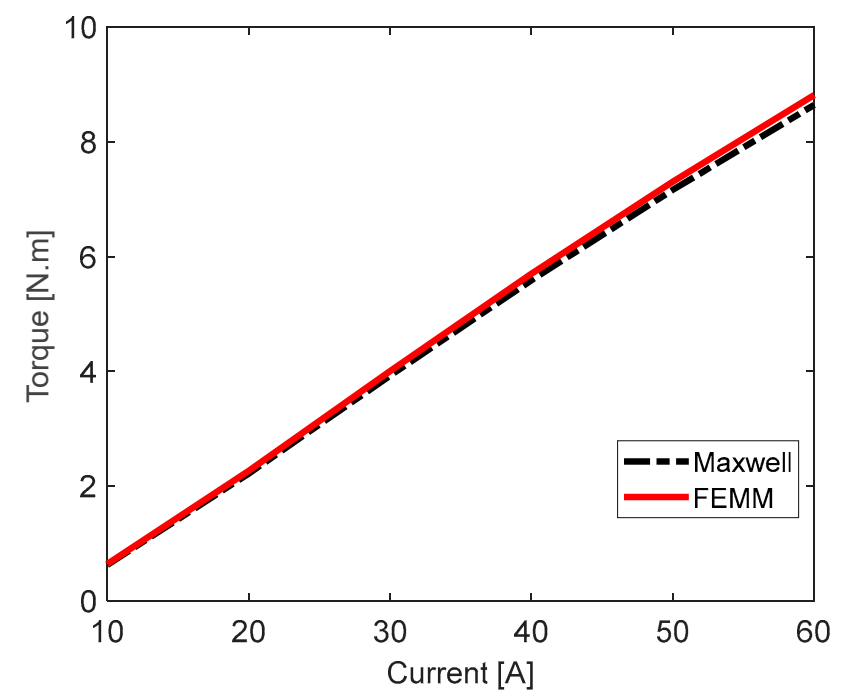

Figure 10. Torque of the SRM as a function of stator current amplitude at $2000 \mathrm{rpm}$.

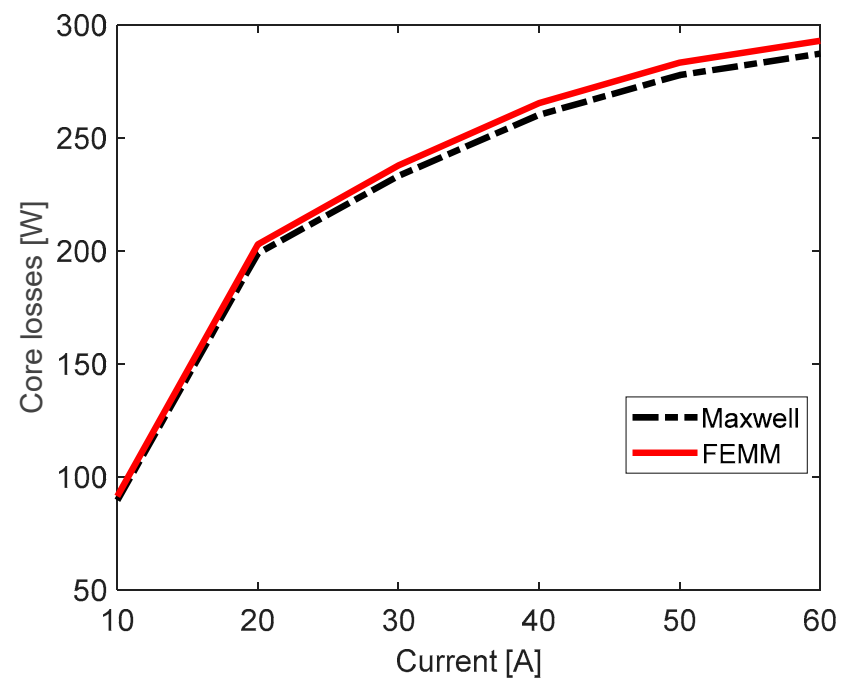

Figure 11. Core losses as a function of stator current at $2000 \mathrm{rpm}$. 


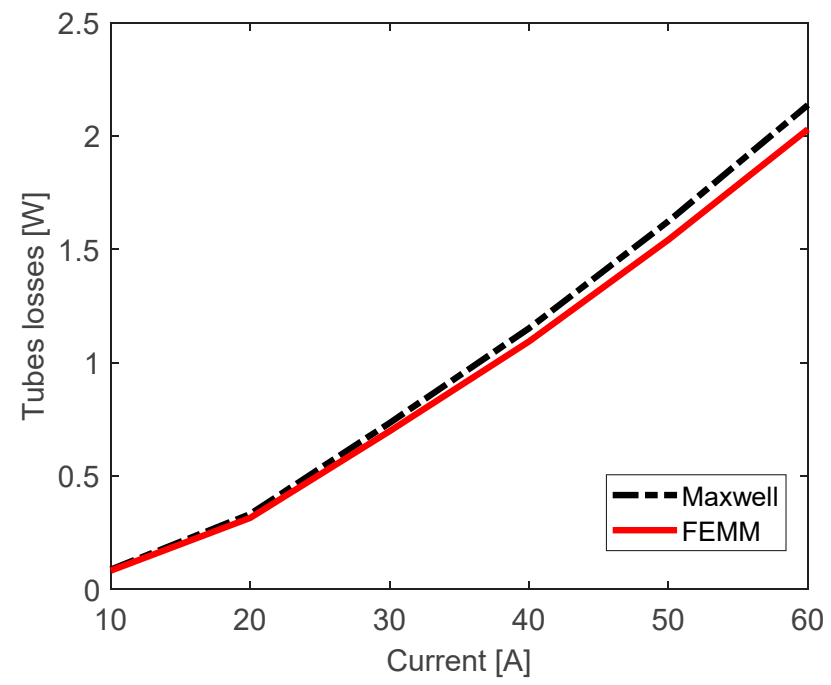

Figure 12. Eddy current losses of the cooling tubes as a function of stator current at $2000 \mathrm{rpm}$.

\section{Experimental Validation}

In order to validate the proposed loss computation method presented before, an experimental test bench was constructed as shown in Figure 13. Figure 13 (left) shows the complete test bench. The stator coils had 25 turns each and the coils were connected in series as shown in Figure 2. The cooling tube material was a stainless steel with a wall thickness of $1 \mathrm{~mm}$. The stator winding was connected to a controlled (amplitude and frequency) pure sinusoidal voltage supply. Figure 13 (right) shows the stacked stator with inserted cooling tubes and concentrated windings.
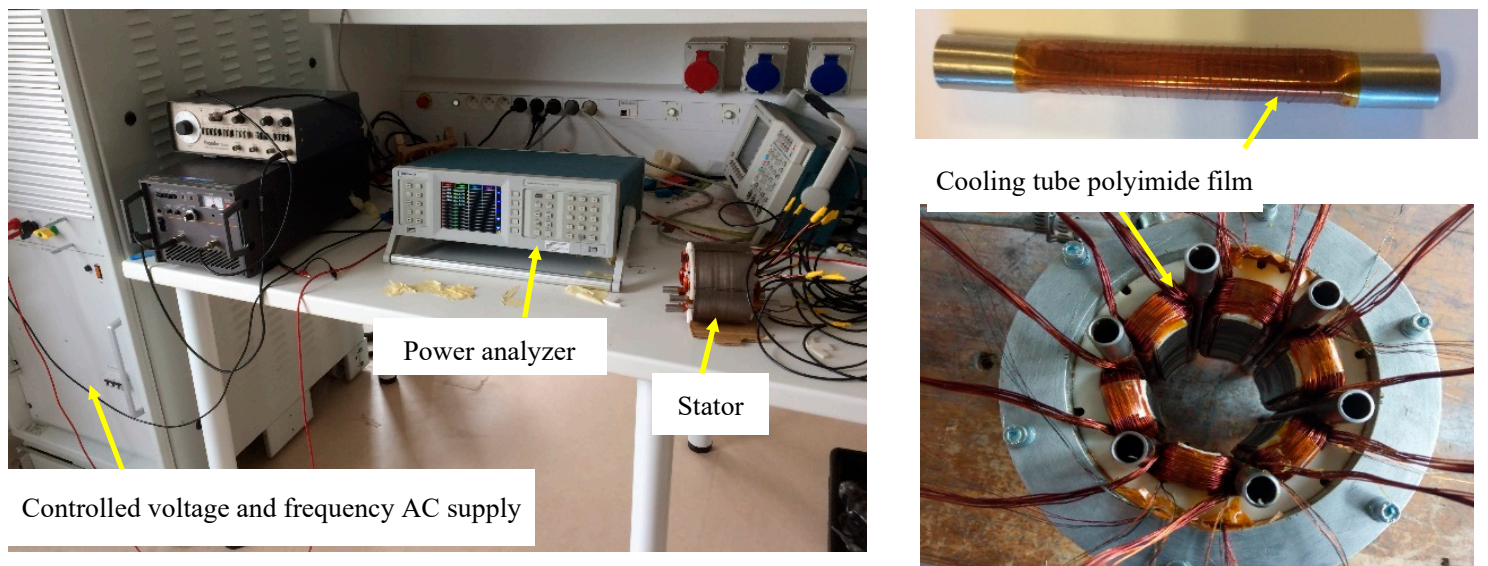

Cooling tube polyimide film

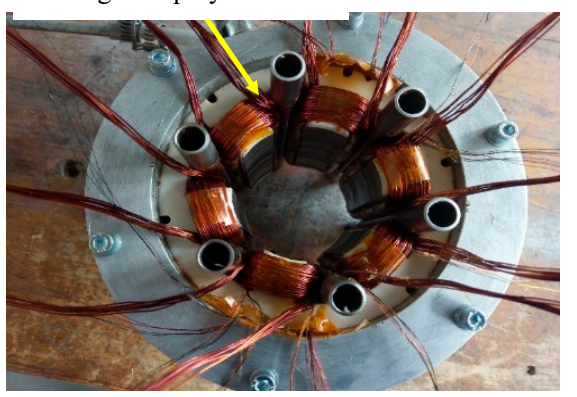

Figure 13. Photograph of (left) complete experimental test bench, (right) stacked stator having concentrated windings and six cooling tubes between the windings.

Firstly, the characteristics i.e., magnetization and loss curves of the steel laminations that were used were measured to obtain the parameters of the iron loss model, see Equation (3). Figure 14 shows the steel laminations of the motor. Figure 15 shows the measured and simulated specific iron losses of the laminations for different magnetic induction and frequencies up to $1.5 \mathrm{~T}$ and $400 \mathrm{~Hz}$ respectively. It was evident that the simulated loss model predicted similar iron losses value as of the measurements, with an acceptable error of maximum $10 \%$.

Figure 16 reports the measured and simulated power losses of the stator components (copper, core and tubes) at several currents and at a supply frequency of $200 \mathrm{~Hz}$. Good matching between the measured and the obtained simulated losses was observed. In addition, some difference between the 
results was noticed at high currents. This was mainly due to the copper losses variation as a result of the variation of the coil temperature; this was because the stator coils were naturally cooled.

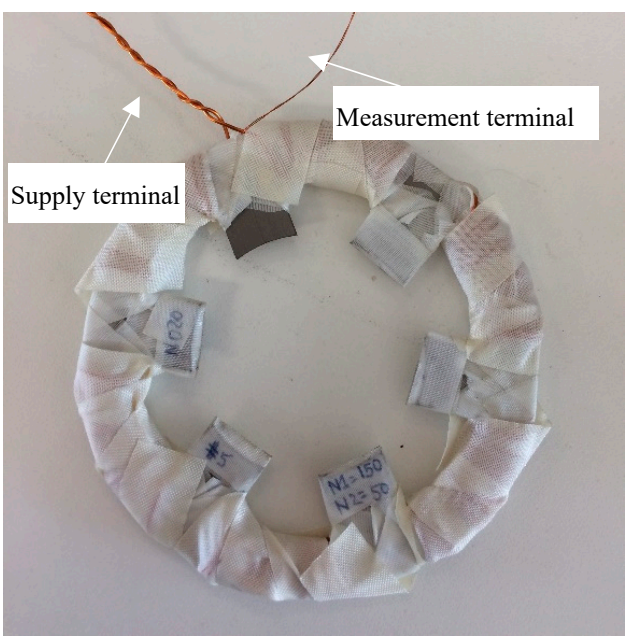

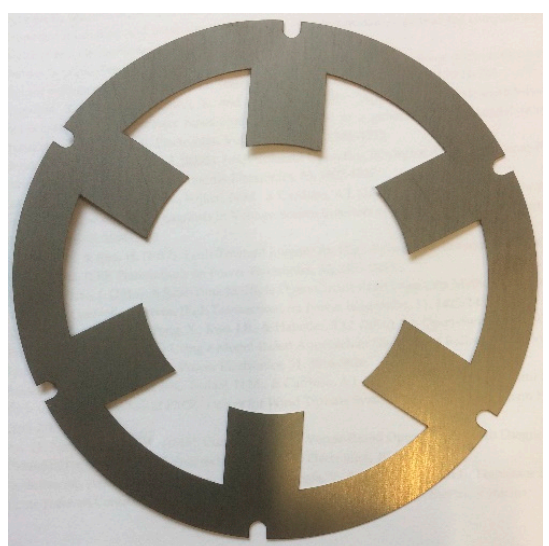

(b)

(a)

Figure 14. Photograph of six-toothed stator laminations: (a) the employed laminations for magnetization and loss curves measurements and (b) one steel lamination.

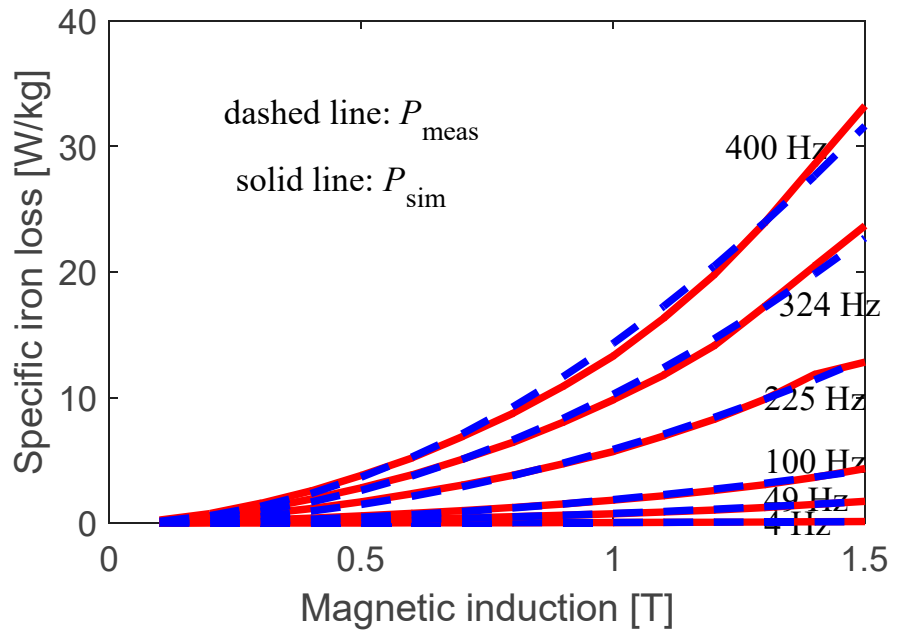

Figure 15. Specific iron loss versus the flux density for several frequencies.

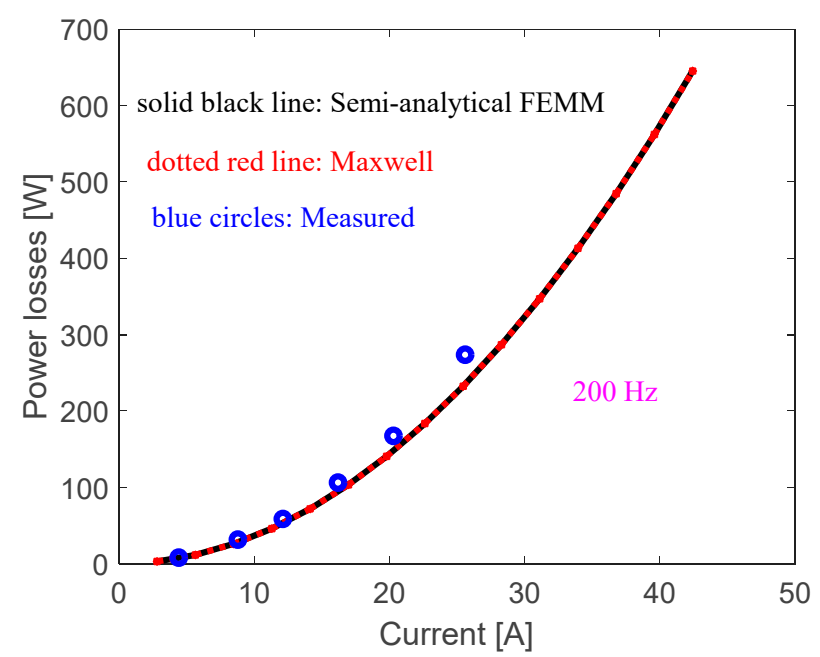

Figure 16. Simulated and measured power losses of the stator (copper + iron + tubes) at $200 \mathrm{~Hz}$. 


\section{Conclusions}

This paper proposed a simple and an accurate combined semi-analytical finite element method to calculate the losses of electric machines with cooling tubes. The 2D magnetostatic solution of the magnetic field was obtained e.g., using the free package "FEMM". Then, the eddy current loss in the tubes was computed based on analytical equations. In addition, the iron core loss could be obtained. The proposed method was generic and could be applied to any electromagnetic device.

To validate the proposed method, two cases were investigated i.e., a six-toothed stator of a switched reluctance electric machine (SRM), in which six cooling tubes were inserted between the coils and full rotating SRM. The results of the proposed method were validated by both the 2D transient simulations of the commercial package "ANSYS Maxwell" and also by experimental measurements. It was found that the proposed method was an effective method to calculate the losses in the cooling tubes as well as in the iron core with almost a free cost.

Author Contributions: Conceptual approach, M.N.F.I. and P.S.; data curation M.N.F.I.; software M.N.F.I.; calculations and modeling, M.N.F.I.; writing of original draft, M.N.F.I.; visualization, M.N.F.I. and P.S.; review and editing, M.N.F.I. and P.S.

Funding: The research was financially supported by Flanders Make, the strategic research center for manufacturing industry and the HERMESFONDS in the framework of the "HIPERCOOL" project (HBC.2016.0463).

Acknowledgments: The authors would like to thank Andries Daem and Abdalla Mohamed for assisting in the experimental work.

Conflicts of Interest: The authors declare no conflict of interest.

\section{References}

1. Jung, H.; Park, G.; Kim, D.; Jung, S. Optimal design and validation of IPMSM for maximum efficiency distribution compatible to energy consumption areas of HD-EV. IEEE Trans. Magn. 2017, 53, 8201904. [CrossRef]

2. Fatemi, A.; Ionel, D.M.; Popescu, M.; Chong, Y.C.; Demerdash, N.A.O. Design optimization of a high torque density spoke-type PM motor for a formula E race drive cycle. IEEE Trans. Ind. Appl. 2018, 54, 4343-4354. [CrossRef]

3. Rodriguez, M.; Sanchez, J.; Perez, A.; Martinez, D. Complete ensemble empirical mode decomposition on FPGA for condition monitoring of broken bars in induction motors. Math. J. 2019, 7, 783. [CrossRef]

4. Ibrahim, M.N.; Sergeant, P.; Rashad, E.M. Synchronous reluctance motor performance based on different electrical steel grades. IEEE Trans. Magn. 2015, 51, 7403304. [CrossRef]

5. Ibrahim, M.N.F.; Abdel-Khalik, A.S.; Rashad, E.M.; Sergeant, P. An improved torque density synchronous reluctance machine with a combined star-delta winding layout. IEEE Trans. Energy Convers. 2018, 33, 1015-1024. [CrossRef]

6. Lindh, P.; Petrov, I.; Immonen, P.; Pyrhönen, J.; Niemelä, M.; Anttila, J.; Paakkinen, M.; Scherman, E. Performance of a direct-liquid-cooled motor in an electric bus under different load cycles. IEEE Access 2019, 7,86897-86905. [CrossRef]

7. Huang, J.; Naini, S.S.; Miller, R.; Rizzo, D.; Sebeck, K.; Shurin, S.; Wagner, J. A hybrid electric vehicle motor cooling system-Design, model, and control. IEEE Trans. Veh. Tech. 2019, 68, 4467-4478. [CrossRef]

8. Dessouky, Y.G.; Williams, B.W.; Fletcher, J.E. Cooling enhancement of electric motors. IEE Proc. Electric Power Appl. 1998, 145, 57-60. [CrossRef]

9. Ghorbanian, V.; Hussain, S.; Hamidizadeh, S.; Chromik, R.; Lowther, D. The role of temperature-dependent material properties in optimizing the design of permanent magnet motors. IEEE Trans. Magn. 2018, 54, 8101104. [CrossRef]

10. Lim, S.; Min, S.; Hong, J. Optimal rotor design of IPM motor for improving torque performance considering thermal demagnetization of magnet. IEEE Trans. Magn. 2015, 51, 8202405. [CrossRef]

11. Prakht, V.; Dmitrievskii, V.; Kazakbaev, V.; Oshurbekov, S.; Ibrahim, M.N. Optimal design of a novel three-phase high-speed flux reversal machine. Appl. Sci. 2019, 9, 3822. [CrossRef] 
12. Gai, Y.; Kimiabeigi, M.; Chong, Y.C.; Widmer, J.; Deng, X.; Popescu, M.; Gross, J.; Staton, D.A.; Steven, A. Cooling of automotive traction motors: schemes, examples, and computation methods. IEEE Trans. Ind. Electron. 2019, 66, 1681-1692. [CrossRef]

13. Dong, J.; Huang, Y.; Jin, L.; Guo, B.; Lin, H.; Dong, J.Y.; Cheng, M.; Yang, H. Electromagnetic and Thermal analysis of open-circuit air cooled high-speed permanent magnet machines with gramme ring windings. IEEE Trans. Magn. 2014, 50, 8104004. [CrossRef]

14. Tüysüz, A.; Meyer, F.; Steichen, M.; Zwyssig, C.; Kolar, J.W. Advanced cooling methods for high-speed electrical machines. IEEE Trans. Ind. Appl. 2017, 53, 2077-2087. [CrossRef]

15. Rahman, N.A.; Bostanci, E.; Fahimi, B. Thermal analysis of switched reluctance motor with direct in-winding cooling system. In Proceedings of the IEEE Conference on Electromagnetic Field Computation (CEFC), Miami, FL, USA, 13-16 November 2016.

16. Liu, Z.; Winter, Z.; Schier, M. Direct coil cooling of a high performance switched reluctance machine (SRM) for EV/HEV applications. SAE Int. J. Alt. Power 2015, 4, 162-169. [CrossRef]

17. Kim, H.; Kim, K.; Jo, Y.; Hur, J. Optimization methods of torque density for developing the neodymium free spoke-type BLDC motor. IEEE Trans. Magn. 2013, 49, 2173-2176. [CrossRef]

18. Schiefer, M.; Doppelbauer, M. Indirect slot cooling for high-power density machines with concentrated winding. In Proceedings of the IEEE International Electric Machines \& Drives Conference, Coeur d'Alene, ID, USA, 10-13 May 2015; pp. 1820-1825.

19. Zhu, S.; Chen, W.; Xie, M.; Liu, C.; Wang, K. Electromagnetic performance comparison of multi-layered interior permanent magnet machines for EV traction applications. IEEE Trans. Magn. 2018, 54, 8104805. [CrossRef]

20. Yin, H.; Huang, S.; Li, H. Study on the Influence of Internal Water Cooling System on the Loss of Permanent Magnet Synchronous Motor. AIP Conf. Proc. 2018, 1971. [CrossRef]

21. Liang, Y.; Bian, X.; Yu, H.; Li, C. Finite-element evaluation and eddy-current loss decrease in stator end metallic parts of a large double-canned induction motor. IEEE Trans. Ind. Electron. 2015, 62, 6779-6785. [CrossRef]

22. Pyrhonen, J.; Jokinen, T.; Hrabovcova, V. Design of Rotating Electrical Machines; Wiley: Hoboken, NJ, USA, 2008.

23. Simao, C.; Sadowski, N.; Batistela, N.J.; Bastos, J.P.A. Evaluation of hysteresis losses in iron sheets under dc-biased inductions. IEEE Trans. Magn. 2009, 45, 1158-1161. [CrossRef]

24. Zhu, S.; Cheng, M.; Dong, J.; Du, J. Core loss analysis and calculation of stator permanent-magnet machine considering dc-biased magnetic induction. IEEE Trans. Ind. Electron. 2014, 61, 5203-5212. [CrossRef]

25. Lin, D.; Zhou, P.; Fu, W.N.; Badics, Z.; Cendes, Z.J. A dynamic core loss model for soft ferromagnetic and power ferrite materials in transient finite element analysis. IEEE Trans. Magn. 2004, 40, 1318-1321. [CrossRef] 